Methods Patients undergoing resection of ovarian, uterine, or cervical cancer between 2005-2019 were identified using the NSQIP database. Body mass index (BMI), weight loss, and albumin were used to evaluate whether patients met various malnutrition criteria (severe, ESPEN1, ESPEN2, ACS, mild, albumin $<3.5 \mathrm{~g} / \mathrm{dL}$; figure 1 ). Outcomes included 30-day major post-operative complications, readmission, and reoperation. Modified Poisson regression was used to estimate the association between each definition and outcomes using risk ratios (RR) and 95\% confidence intervals (CI).

Results Ovarian cancer patients meeting ESPEN2 had higher risk of readmission ( $R R$ 1.69;1.29-2.20), reoperation (RR $2.53 ; 1.70-3.77$ ), and complications (RR 1.36; 1.20-1.54; Table). Uterine cancer patients meeting ACS had increased risk of readmission ( $R R$ 2.74;2.09-3.59), reoperation ( $R R$ $3.61 ; 2.29-5.71$ ) and complications (RR 3.92;3.40-4.53). For cervical cancer, albumin $<3.5$ was associated with readmission (RR 1.48;1.01-2.19), reoperation (RR 2.25;1.17-4.34), and complications (RR 2.59;2.11-3.17). Albumin $<3.5$ was also associated with increased risk of all outcomes for ovarian and uterine cancer patients.

Conclusions The malnutrition definitions predicting the highest number of adverse post-operative outcomes varies by cancer type. Major complications, readmission, and reoperation were

\begin{tabular}{|c|c|c|c|c|c|}
\hline $\begin{array}{c}\text { Severe } \\
\text { Malnutrition } \\
\text { BMI }<18.5+ \\
\text { weight loss }{ }^{*}\end{array}$ & $\begin{array}{c}\text { ESPEN } 1 \\
\text { If }<70 \text { yo: BMI 18.5- } \\
20+\text { weight loss* } \\
\text { OR } \\
\text { If } 270 \text { yo: BMI 18.5- } \\
22+\text { weight loss* }\end{array}$ & $\begin{array}{c}\text { ESPEN } 2 \\
\text { BMI }<18.5\end{array}$ & $\begin{array}{c}\text { ACS } \\
\text { If }<70 \text { yo: BMI } \\
>20+\text { weight } \\
\text { loss* } \\
\text { OR } \\
\text { If } \geq 70 \text { yo: BMI } \\
>22+\text { weight } \\
\text { loss* }\end{array}$ & $\begin{array}{c}\text { Mild } \\
\text { Malnutrition } \\
\text { If }<70 \text { yo: } B M \mid \\
18.5-20 \\
O R \\
\text { If } \geq 70 \text { yo: } B M \mid \\
18.5-22\end{array}$ & $\begin{array}{l}\text { Albumin } \\
<3.5 \mathrm{~g} / \mathrm{dL}\end{array}$ \\
\hline
\end{tabular}

Abstract OP026/\#45 Figure 1 Malnutrition definitions

Abstract OP026/\#45 Table 1 Association between malnutrition definitions and outcones by cancer presented as risk ratios and $95 \%$ confidence intervals

\begin{tabular}{|c|c|c|c|}
\hline & Uterine & Cervical & Ovarian \\
\hline \multicolumn{4}{|c|}{ Major complication(s) $^{1}$} \\
\hline Mild malnutrition & $1.33(1.14,1.55)$ & $1.69(1.30,2.18)$ & $1.16(1.07,1.26)$ \\
\hline Severe malnutrition & $7.85(6.10,10.11)$ & $4.83(2.54,9.21)$ & $2.05(1.66,2.53)$ \\
\hline ESPEN 1 & $3.65(2.23,5.97)$ & $3.62(1.53,8.54)$ & $1.65(1.34,2.01)$ \\
\hline ESPEN 2 & $1.74(1.36,2.22)$ & $1.92(1.32,2.79)$ & $1.36(1.20,1.54)$ \\
\hline ACS & $3.92(3.40,4.53)$ & $3.51(2.49,4.95)$ & $1.67(1.52,1.82)$ \\
\hline Albumin $<3.5 \mathrm{~g} / \mathrm{dL}^{3}$ & $3.74(3.48,4.02)$ & $2.59(2.11,3.17)$ & $1.74(1.65,1.83)$ \\
\hline \multicolumn{4}{|c|}{ Unplanned readmission $^{2}$} \\
\hline Mild malnutrition & $1.17(0.93,1.48)$ & $1.46(1.00,2.15)$ & $0.96(0.78,1.18)$ \\
\hline Severe malnutrition & $\cdots$ & - & $\cdots$ \\
\hline ESPEN 1 & - & - & $\ldots$ \\
\hline ESPEN 2 & $1.15(0.74,1.79)$ & $1.33(0.71,2.50)$ & $1.69(1.29,2.20)$ \\
\hline ACS & $2.74(2.09,3.59)$ & $2.45(1.24,4.82)$ & $1.36(1.06,1.75)$ \\
\hline Albumin $<3.5 \mathrm{~g} / \mathrm{dL}^{3}$ & $2.38(2.10,2.69)$ & $1.48(1.01,2.19)$ & $1.28(1.11,1.47)$ \\
\hline \multicolumn{4}{|c|}{ Unplanned reoperation $^{2}$} \\
\hline Mild malnutrition & $0.98(0.61,1.58)$ & $0.91(0.38,2.21)$ & $0.95(0.66,1.38)$ \\
\hline Severe malnutrition & - & - & - \\
\hline ESPEN 1 & - & - & - \\
\hline ESPEN 2 & $1.25(0.56,2.77)$ & $1.42(0.46,4.38)$ & $2.53(1.70,3.77)$ \\
\hline ACS & $3.61(2.29,5.71)$ & $2.23(0.57,8.69)$ & $1.09(0.65,1.81)$ \\
\hline Albumin $<3.5 \mathrm{~g} / \mathrm{dL}^{3}$ & $2.56(2.01,3.25)$ & $2.25(1.17,4.34)$ & $1.31(1.01,1.70)$ \\
\hline \multicolumn{4}{|c|}{$\begin{array}{l}{ }^{1} \text { Major complications included unplanned intubation, ventilator use }>48 \text { hours, sepsis, septic shock, } \\
\text { pneumonia, deep incisional surgical site infection, acute renal failure, organ space surgical site } \\
\text { infection, renal insufficiency, wound disruption, pulmonary embolism, myocardial infarction, cardiac } \\
\text { arrest requiring CPR, stroke/cerebrovascular accident with neurological deficit, deep vein thrombosis, } \\
\text { blood transfusion } \\
{ }^{2} \text { Outcome only available starting in } 2011 \\
{ }^{3} \text { Only among the subset of patients with pre-operative serum albumin } \\
\ldots-=\text { models did not converge due to low event rate after dividing by malnutrition definition and cancer } \\
\text { type }\end{array}$} \\
\hline
\end{tabular}

associated with $\mathrm{BMI}<18.5$ alone for ovarian cancer (ESPEN2), with $10 \%$ recent weight loss and a normal or overweight BMI for uterine cancer (ACS), and with albumin $<3.5$ for all cancers. These criteria may be useful for cancer-specific preoperative planning.

\section{OP027/\#469 ELECTRONIC PATIENT-REPORTED OUTCOME (EPRO) MEASURES IN GYNECOLOGIC ONCOLOGY: INITIAL EXPERIENCE AFTER WORKFLOW IMPLEMENTATION}

J Noh*, C-H Choi, T-J Kim, J-W Lee, Y-Y Lee. Samsung Medical Center, Obstetrics and Gynecology, Seoul, Korea, Republic of

\subsection{6/ijgc-2021-IGCS.44}

Objectives The aim of this study was to report our initial experience with a mobile app of electronic patient-reported outcome (ePRO) for patients undergoing treatment for gynecologic malignancies.

Methods The target patients were introduced to a mobile app in which they could answer to pre-selected questions. The questions included the quantification of fatigue, pain, anxiety, dizziness, hair loss, peripheral numbness, tingling, nausea, myalgia, depression, insomnia and others. Two different sets of questions were used for surgery and chemotherapy.

Results A total of 61 patients reported more than 29,000 data points. The mean ages were $53.0 \pm 12.2$ years old for the surgery group and $54 \pm 13.2$ years old for the chemotherapy group. The median numbers of app use during the course of treatment was 10 and 13 for the surgery and chemotherapy groups, respectively. The mean duration of app use to complete each report was $8 \pm 13$ minutes for the surgery and 7 \pm 12 minutes for the chemotherapy groups. This did not differ by age groups, suggesting that there were no difficulties of using the app for any specific age group. ePRO was able to detect the occurrence of both expected and unexpected side effects. In addition, a gradual increase in the severity of side effects over the course of treatment, especially for those who received chemotherapy, could be observed.

Conclusions ePRO have a great potential to improve patient care in gynecologic oncology by providing a comprehensive documentation of symptoms and side effects.

\section{Surgical Film Abstracts}

\section{SF001/\#65 LAPAROENDOSCOPIC RADICAL TRACHELECTOMY AND PELVIC LYMPHADENECTOMY WITHOUT UTERINE MANIPULATOR}

H Lu*, C Huo, Z Lin. The Sun Yat-Sen memorial hospital of Sun Yat-Sen University, Gynecologic Oncology, Guangzhou, China

\subsection{6/ijgc-2021-IGCS.45}

Introduction In face of the postponement in marital and reproductive age in the modern society, most of the patients with cervical cancer have not conceived yet or still bear fertility plans. We herein introduce the Laparoendoscopic radical trachelectomy (LRT) a surgery called radical trachelectomy through a minimally invasive approach for young patients with cervical cancer to preserve fertility without compromising the oncology outcomes. 
Description A 29-year-old, nulliparous woman with stage IB1 cervical cancer received the LRT plus lymphadenectomy with enclosed colpotomy and without manipulator. Instead of using a uterine manipulator, uterine suspension was adopted. We suture bilateral round ligaments to form a coil with the anterior wall of the uterus which help remain the integrity of the uterus. After the branches of the uterine artery were separated, the uterine branch was retained.Reconstruction of the residual cervix and vagina was performed by the 'cuff-sleeve' suture method. The anterior and posterior walls of the vagina were sutured with 2 ' $U$ ' shapes respectively with special care given to the uterine branches of the uterine artery. At the end of the surgery, a stent was set trans-vaginally in case of cervical stenosis. The 'neocervix' was restored to its original anatomy after 6 months.Till now, reproductive function and sexual health is satisfied for the patient.

Conclusions LRT with unique modifications is safe and feasible for patients with early stage cervical cancer to preserve fertility. Further study shall be in place to better evaluate the postoperative efficacy and pregnancy outcomes of such procedure.

\section{SF002/\#332 SENTINEL LYMPH NODE MAPPING FOR CERVICAL CANCER: A PRACTICAL ILLUSTRATION OF USING ICG DURING A LAPAROTOMY}

${ }^{1} \mathrm{M}$ Burling, ${ }^{2} \mathrm{D}$ Krishnan*, 'L Foster, ${ }^{1} \mathrm{~A}$ Brand, ${ }^{2} \mathrm{U}$ Herbst. 'Westmead Hospital, Gynaecological Oncology, Westmead, Australia; 'Westmead Hospital, Gynaeoncology, Westmead, Australia

10.1136/ijgc-2021-IGCS.46

We have created a surgical video to demonstrate the sentinel lymph node mapping in cervical cancer during a laprotomy. Sentinel lymph node (SLN) mapping is an emerging technique to be used in the surgical management of women with cervical cancer. Multiple studies including SENTICOL 2 has shows the accuracy of using SLN biopsy in cervical cancer treatment [1]. This approach has mainly been used with minimally invasive surgery. However, since the publication of the LACC trial in 2018, there has been a evidence based shift to open radical hysterectomy for early stage cervical cancer [2]. We aim to display how to perform SLN biopsy with indocyanine green (ICG) dye, using a laparoscopic camera even in open surgery. The video footahe were gleaned from an unedited surgical film recorded at our institute. We conclude that SLN mapping and biopsy with ICG during a laparotomy is feasible and achievable.

\section{SF003/\#661 TOTAL PELVIC EXENTERATION AND PERINEAL RECONSTRUCTION FOR RECURRENT CERVICAL CANCER}

A Thomas*, R Chandy, A Sebastian, R Mittal, JK Ramireddy, R Paul Mukha, M Lamba, A Peedicayil. Christian Medical College, Vellore, Gynecologic Oncology, Vellore, India

\subsection{6/ijgc-2021-IGCS.47}

Background and Introduction Salvage procedures for recurrent and residual cervical cancer following radical chemo radiation can be offered to patients with motivation and willingness to undergo massive operative procedures. It needs the skill of a multidisciplinary team who can contribute to various aspects of this complicated procedure. Description of the technique Here we describe Total Pelvic exenteration in a 49 year old lady with residual disease of cervical cancer who after chemo radiation for a bulky stage IIIB $(8 \mathrm{~cm})$ endocervical adenocarcinoma of the cervix was found to have central residual disease infiltrating bladder, vagina, anal canal and rectum. She was offered total exenteration after 3 cycles of chemotherapy with Paclitaxel and Carboplatinum after ruling out metastatic disease with a PET-CT. She was operated upon by a team comprising of urologist, colorectal surgeon, gynaecologic oncologists and plastic surgeon. She underwent Total Pelvic exenteration with enbloc removal of uterus with vagina, urinary bladder, urethra, rectum and and anal canal. The ureters were diverted into an ileal conduit by Wallace technique and the colon was diverted into a Hartmans Pouch The vulval defect was reconstructed by gracilis myocutanaeous flap repair over a vicryl mesh. Post operatively her wound healed well and she was discharged on $8^{\text {th }}$ post-operative day. Surgical margins were free of tumour on histopathology. She is alive and well on follow up after 30 months.

Conclusions Salvage procedures for residual and recurrent cervical cancers can result in good survival and quality of life in motivated and surgically fit patients.

\section{SF004/\#153 THE USE OF LIGHTED URETERAL CATHETERS IN DIFFICULT MINIMALLY INVASIVE GYNECOLOGIC ONCOLOGIC SURGERY}

${ }^{1} \mathrm{~J}$ Mejia-Gomez ${ }^{*},{ }^{2} \mathrm{G}$ Lennox, ${ }^{2} \mathrm{~K}$ Pulman, ${ }^{2} \mathrm{~S}$ Sinasac, ${ }^{2} \mathrm{~T}$ Feigenberg. ${ }^{1}$ Mount Sinai Hospital/ University of Toronto, Obstetrics and Gynecology, Toronto, Canada; ${ }^{2}$ Trillium Health Partners/University of Toronto, Gynecologic Oncology, Mississauga, Canada

\subsection{6/ijgc-2021-IGCS.48}

Introduction Over the past decade, the utility of minimally invasive surgery (MIS), laparoscopy and robotics, has significantly increased in gynecologic oncology surgeries. MIS has many advantages Over open surgery including a significant reduction in the length of hospital stay, fewer post-operative complications, and increased patient satisfaction. Ureteral injuries are amongst the most common complication of gynecologic procedures. The presence of large pelvic masses, significant obesity, adhesions and previous radiation can increase the risk of ureteral injuries during gynecologic oncology procedures. Description Our objective is to demonstrate the technique of stent insertion and use. In addition we will demonstrate the use of lighted ureteral stents in difficult selective minimally invasive gynecologic oncology procedures such as surgery on morbidly obese patients, very large pelvic masses, management of adhesions and surgery for patients who were previously treated with pelvic radiation. We will demonstrate the use of lighted ureteral catheters in both laparoscopic and robotic procedures.

Conclusion Lighted Urethral stents can assist the surgeon in identifying the ureter, reduce the needs for extensive retroperitoneal dissection and potentially reduce rates of ureteral injuries. The usage of lighted ureteral catheters/stents are supported in both standard laparoscopic and robotic surgery. Techniques that can support the surgeon to accurately identify the ureters are paramount. 